\title{
Non-resident fathers' holidays alone with their children: experiences, meanings and
}

\section{fatherhood}

Research on family holiday experiences is largely informed by feminist gender representations. True gender scholarship requires a critical appraisal of gender relations that is inclusive of the male voice in family tourism. This exploratory study extends previous research into separated families and their leisure experiences. Our research focuses on the experiences of non-resident fathers who holiday alone with their children and the meanings of these experiences for those fathers. The study is interpretive and informed by a grounded theory analysis of eight semi-structured interviews with non-resident fathers living in Auckland, New Zealand. Our findings reveal the importance of family holidays to family leisure for separated families and for non-resident fathers' relationships with their children. Leisure-based holidays shared with their children are special times for these non-resident fathers to have fun, to teach skills and negotiate values, to explore the meanings of their lives, to (re)build and maintain family relations, and to experience fatherhood.

Keywords: non-resident father; children; fatherhood; leisure; meanings; experiences

\section{Introduction}

Social and economic changes in the last three decades have seen substantial growth in the focus of public policy and social sciences on parenting and fatherhood. What dads actually do with their children, how fathers exercise their roles as parents, and the benefits to parents and children arising from fathers' engagement in their children's lives are of growing community and academic interest (Halle, Moore, Greene, \& LeMenestrel, 1998; Smyth, 2004a, 2005b). This interest is in large part due to the changing nature and structures of families in many countries and regions. It is also due to changing notions and understandings of fatherhood, and of fathers' engagement with their children in ways that benefit fathers, their children and other family members, including the other parent(s) and extended family.

Family structures are very diverse and in some countries are undergoing rapid change (e.g., Australian Institute of Family Studies, 2003). In New Zealand, the notion of 'family' has changed significantly in the past thirty to forty years. The New Zealand Families 
Commission (2008) describes declining marriage rates, the rising number and rate of de facto relationships, and divorce rates of approximately $12 \%$. Although rates of divorce involving children declined in New Zealand between 1996 and 2006 (50\% and 44\% respectively), and less children were impacted by divorce in that period ( 9,445 to 8,075 respectively), there is a large number and high proportion of families in which the father does not live with his child(ren) for a significant amount of time, if at all. According to the Organisation for Economic Co-operation and Development (OECD, 2011), in New Zealand, nearly one in four children live in single-parent homes, and within single-parent households only one in eight children live with their father. The OECD (2011) reported the percentages of all children (under 15 years for Canada and New Zealand; under 18 years for all other countries) in OECD countries, living with one parent in 2007. These data display some significant variations among countries. By way of example, Australia (16.8\%), Canada (22.1\%), France (13.5\%), Germany (15.0\%), Greece (5.3\%), Ireland (24.3\%), Japan (12.3\%), New Zealand (23.7\%), United Kingdom (21.5\%), United States (25.8\%). The OECD predicts the number of sole parent households to continue to rise in all the above countries, with the exception of Germany.

Holidays and leisure travel are important aspects of many families' time together (Shaw, Havitz, \& Delemere, 2008). Family holidays form the balance part of the "core and balance" model of family leisure functioning within a family systems framework (Zabriskie \& McCormick, 2001), where core or everyday leisure provides familiarity and greater cohesion while balance or away from home leisure is related to family adaptability (Buswell et al., 2012). However, despite the number and proportion of families that experience separation and divorce in New Zealand and other countries, research into their leisure travel decisions, behaviours, experiences and the meanings of those balance experiences have attracted little attention from leisure and tourism scholars. Specifically, we know very little about nonresident fathers' travel with their children who do not engage in daily family activities. This situation is in contrast to a growing body of work on non-resident fatherhood and core leisure more generally, which is emerging in leisure studies (e.g., Jenkins, 2009; Jenkins \& Lyons, 2006), family studies (e.g., Amato \& Gilbreth, 1999; Hallman, Dienhart, \& Beaton, 2007; Stewart, 1999) and wider social sciences discourses.

This exploratory study examines the experiences of eight non-resident fathers who go on holidays alone with their children, and the meanings of these experiences for the fathers involved. Our research offers non-resident fathers a voice within a hitherto under-reported social phenomenon of contemporary family life. The research reported in this paper 
complements other studies of the relationships between parenting, fatherhood and family leisure (e.g., Carr, 2011; Harrington, 2009; Jenkins, 2009; Kay, 2009). It acknowledges and contextualises previous research which illustrates how and why leisure, including leisure holidays, is important, if not at times central, to the ways in which non-resident fathers engage with their children and make important contributions to their children's lives. This paper provides new insights into a previously unexplored aspect of family holidays, an important social phenomenon. Our approach and findings provide rich ground for further research into family holidays, making an important contribution in bringing men's voices to the forefront of analyses in beginning to understand how fathers' relationships with their children can be affected by fathering arrangements and specifically their holidays away from home with their children.

\section{Literature review}

Divorce, de facto separation and non-marital childbirth in many countries countries have increased since the 1970s, and a growing number of fathers live separately from their children. Trends in countries such as Australia, Canada, New Zealand, the United States and the United Kingdom reveal increasing diversity in family structures, changes in family legislation and family support arrangements, increased participation in the workforce by women, greater recognition of the need for fathers to be involved in family life, and high rates of absence of fathers from their children's lives (Blankenhorn, 1995; Cabrera, TamisLeMonda, Bradley, Hofferth, \& Lamb, 2000; deVaus, 2004; Jenkins \& Lyons, 2006; Smyth, 2004a, 2004b, 2005a, 2005b). The extent and nature of parents' engagement with their children and notions of parenting and fatherhood are changing as family structures and lifestyles change. The implications of these circumstances, whilst often present in social policy and family studies discourses, are relatively rare in discourses concerning specific and important aspects of family life, such as the interrelated fields of leisure, recreation and travel (e.g., Carr, 2011; Jenkins \& Lyons, 2006). Fatherhood, in particular, has not been prominent in the leisure and tourism studies fields, and 'gender research itself has been relatively blind to men' (Kay, 2006, p. 136). As Such (2009, p. 73) explained in the context of leisure studies:

understanding fatherhood is a relatively new pursuit for leisure scholarship. Contrary to the state of knowledge on motherhood, substantial empirical and theoretical gaps exist in accounting for the relationships between men, their roles as fathers, and their leisure lives ... So dominant is the historical tie between 
fatherhood and 'breadwinning' that leisure as a site for constructing and reconstructing a fatherhood identity is frequently overlooked.

The failure to adequately include non-traditional families in social psychology and sociology discourses was described by Susan Shaw. According to Shaw (1997), studies of family leisure failed to consider 'separated parent families, gay and lesbian families, blended and noncustodial families, and families without children' (p. 98). Despite increasing evidence of fathers' contributions to their children's education, health and wellbeing (Kay, 2006), research on separated fatherhood, masculinities, and holidays as a form of leisure and as aspects of contemporary family life are few. As Jenkins (2013, p. 187) put it:
A better picture of the extent of non-resident father-child contact is being unpacked by researchers in leisure studies and other fields. However, we still do not know enough about how non-resident fathers use their time and what they do with their children during contact and with what effects both with respect to the fathers, the children and their wider families, including the children's mother.

For many separated fathers, contact with their children is important but inadequate (Jenkins, 2009). A growing body of work, however, is being linked to the impacts of separation and divorce on fathers and on fathers' relationships with their children, to fathering and fatherhood in contemporary society, and to the importance of non-resident fathers' engagement with their children for family functioning and fathers' and children's health and wellbeing (e.g., Allen \& Daly, 2007; Amato, 2001; Amato \& Gilbreth, 1999; Jenkins, 2009, 2013; Kay, 2006; Smyth, 2004a, 2004b, 2005a, 2005b). How and why fathers, including nonresident dads, make valuable contributions as parents to their children's lives through their engagement with their children in leisure, recreation and sport is evident in few studies (e.g., Kay, 2009).

Analysing leisure and family holidays in a variety of contexts and settings can enhance our understandings of social relations (see Carr, 2011; Rojek, 2005; Schänzel \& Yeoman, 2015). For example, a growing body of research in different settings and using diverse methodologies reveals that fathers' leisure with their children can enhance and nurture parentchild relationships (Jenkins, 2009; Swinton, Freeman, Zabriskie, \& Fields, 2008, 2009) and help fathers adapt their expectations of leisure activities with their children (Mitchell \& Lasewicz, 2015). Mitchell and Lashewicz's (2015) research concerning generative fathering 
and fathers' leisure with their children with Autism Spectrum Disorder revealed how fathers adapt and nurture their relationships with their children through leisure. One father (Jason) in that study described the importance of ski and camping trips:

We've travelled. We go away. We go skiing ... we've really put forth even though ... sometimes it's the biggest nightmare (laughter) you've ever had. Really, you know why are we doing this? We're in the car for eight hours ... but I think it's really contributed to him understanding the big picture of the world (Mitchell and Lashewicz's, 2015, p. 138).

Examinations of the interactions between fathers and children during leisure and play time have failed to adequately consider how being a non-resident dad affects leisure choices, behaviours, perceptions and meanings not only for the fathers involved, but also for the children. Regardless of how much time fathers are able or permitted to spend with their children, the freedom fathers experience within a leisure context should afford them the opportunity to have 'quality time' with their children and to engage in mutually beneficial activities which might have benefits for wider family members (Caruana \& Ferro, 2004; Jenkins, 2009; Fountain, Schänzel, Stewart, \& Körner, 2015). There is growing evidence that meaningful family relationships can develop and flourish in family leisure settings.

Family travel is predicted to grow at a faster rate than all other forms of leisure travel, mainly because it represents a way to reunite the family and for family members to spend time with each other, away from the demands of work and school (Schänzel \& Yeoman, 2015). Family leisure travel research is largely focused on nuclear families (Carr, 2011; Obrador, 2012), and studies of family holiday experiences, with few exceptions, have been primarily informed by feminist approaches and traditions (Schänzel \& Smith, 2011). These studies highlight the never-ending physical and emotional work of motherhood both at home and when travelling (i.e. Mottiar \& Quinn, 2012; Small, 2005). Although fathers have recently been recognised as important actors with a specific voice in the holiday experiences and practices of the family (Costa, 2014b; Schänzel \& Smith, 2011), these studies are mostly based on heterosexual couples. A recent book by Thurnell-Read and Casey (2014) entitled Men, Masculinities, Travel and Tourism is an important contribution and exception to the travel and tourism literature, comprised of a collection of chapters focusing on men, masculinity and men's travel and interactions with other men and women. It includes a chapter by Rosalina Costa, whose work shows the emergence of ephemeral masculinities pervasive to partnering and fathering on family-centred holidays that fade away when couples return home. 
Although broader discussions on masculinities and gender relations in leisure and tourism are emerging (Lyons, 2006; Pringle, Kay, \& Jenkins, 2011; Thurnell-Read \& Casey, 2014), fathers are largely invisible apart from their joint parenting voice (Fu, Lehto, \& Park, 2014; Gram, 2005; Shaw et al., 2008), or are presented in comparison with mothers, from a women's perspective (Anderson, 2001). Recognition of the intersection between the gender roles of mothers and fathers in leisure travel research, and their femininities and masculinities, or 'true gender research', represents a significant research gap (Schänzel \& Smith, 2011). True gender scholarship requires a more critical appraisal of gender relations that is inclusive of the male voice in family holidays and broader leisure travel experiences. A study by Schänzel and Smith (2011) found that fathers do take on primary responsibilities on family holiday. They are entertainers of the children and facilitators of mothers pursuing their own interests, roles which have not been acknowledged in the tourism literature in particular. This situation in traditional families contrasts sharply with the oversimplified concept of the 'Disneyland Dad' which was used to describe non-resident fathering (Stewart, 1999). It was argued non-resident fathers spoil their children and strive to make visits 'fun' and conflict free rather than assuming any real parenting responsibilities (Stewart, 1999). Stewart's research was not specific to family leisure and family holidays and did not seek to understand fathers' experiences of leisure time with their children, the deeper meanings of leisure and holidays for non-resident fathers and the significance of leisure to family and wider social relationships.

\section{Methods}

Few have explored the qualitative dimensions of non-resident fathers' contact with their children in the contexts of leisure and leisure travel. None have done so with specific reference to leisure travel and holidays, making this the first study on non-resident fathers' leisure with their children within a travel setting. The aim of this explorative study was to understand the experiences and meanings gained by non-resident fathers travelling alone with their children. On the basis of the literature review and the authors' previous experiences in undertaking studies involving fathers and their leisure with their children, three initial research questions helped inspire and inform the study:

(1) What do fathers do when they are on holiday alone with their children?

(2) How do these fathers experience and remember their time on holiday with their children? 
(3) What meanings do these holidays have for the fathers, particularly in terms of fathering?

These questions were used to help semi-structure the interviews and to develop more detailed questions about non-resident fathers' activities with their children, how they spent time with and without their children during holidays, what they remember about their most recent holidays with their children, and their holiday experiences. The questions, detailed below, allowed fathers to recount their stories and for themes to emerge.

\section{Sampling}

The complexity of family arrangements in the context of non-resident fatherhood is evident from the above discussion. This complexity together with the lack of knowledge regarding the travel choices and behaviours of non-resident fathers who holiday away from home with their children means a sampling frame for our study is not available. Moreover, the difficulties in recruiting fathers in family and leisure studies have been widely acknowledged (Carr, 2006; Jenkins, 2009). In these circumstances where fathers' voices are critical to our understandings, qualitative methodologies are well suited to reveal the experiences, meanings and impacts of their holidays and broader leisure activities with their children (Jenkins, 2009; Jenkins \& Lyons, 2006). The choice of methodology is underpinned by the philosophical perspective of interpretivism, with the goal of understanding the complex world of the lived experience from the point of view of those who live it (Denzin \& Lincoln, 2000; Phillimore \& Goodson, 2004). As Swinton et al. (2009, p. 163) concluded, 'further examination into the meaning and importance of leisure for non-resident fathers and their children ... would also benefit from qualitative approaches'.

Semi-structured in-depth interviews were conducted in February/March 2014 with eight non-resident fathers who had recently travelled on holidays alone with their children. Non-resident fathers residing in Auckland, New Zealand, were recruited in a non-random manner, which limits generalisations of the findings to the study's participants. The recruitment of fathers was essential to allow access to, and focus upon, the personal stories of fathers holidaying alone with their children. The sample was initially one of convenience, in that the first author used her contacts and networks to identify respondents. The sample then expanded by snowball effect in that respondents suggested other respondents who might be contacted. The sample was also purposive in that fathers were selected on the basis that during their holidays with their children, they travelled alone with them. Only the biological or adoptive fathers of children for whom they do not normally have custody for more than 
approximately $50 \%$ of the time, and with whom they do not share the same home address outside of those contact hours, were recruited for the study.

Sampling in qualitative research often involves the recruitment of a small number of participants so as to study a phenomenon in rich depth and detail. For exploratory studies such as this, there are no specified rules for determining sample size. By way of examples, Wearing, Wearing, McDonald and Wearing (2015) recently published a paper reporting on the links between leisure and computer games based on a conversation between an academic father and his 14-year-old son. McCarville, Shaw and Ritchie (2013) based their exploratory study on nine self-defined 'avid shoppers' using similar convenient and snowball sampling techniques. Such (2006) interviewed 14 self-selected dual-earner couples with dependent children, with those self-selecting from predominantly higher socio-economic groups. Fathers were interviewed separately, and the findings reported in the paper focused largely on the responses of the fathers. Our interviews with eight fathers revealed very detailed information of which only selected themes are reported in this paper.

In this exploratory study, our findings are necessarily limited and we cannot describe how representative our sample is of the wider population; nor can we generalise findings. However, the diversity in fathers and their fathering behaviours and family arrangements provide initial, nuanced insights, increase our understanding of the phenomenon and pose new questions and orientations for potentially valuable research regarding an important social phenomenon. Individuals recounted through their own voices their experiences. Each father's story is unique and shaped by their personal circumstances. We suggest our approach and methodology have provided new scope for more detailed and rigorous research, but nonetheless acknowledge the important limitations in our sampling design.

\section{The interviews}

The interviews with participants averaged just over one hour, and ranged from 50 minutes to 1.5 hours. All interviews were digitally recorded and later transcribed. The interviews were conducted at locations such as cafes, which were convenient and comfortable for the fathers, and at locations which were chosen by them. Fathers were asked questions about such matters as:

- the background to their holiday experiences with their children (frequency, length and destinations);

- the importance and meanings of those holidays;

- whether and how these holidays differed (if at all) from everyday leisure time; 
- their most recent holiday experiences;

- the best time they had on their holiday;

- negative aspects of the holidays;

- successful and unsuccessful choices made by them regarding holiday destinations and other aspects of the holiday;

- whether they spend time away from children whilst on holiday with them and what this means to fathers; and

- their overall holiday experiences.

Each question presented opportunities for deeper exchanges and probing. The emphasis was on providing the fathers with a voice to reveal their experiences and the deeper meanings they held in terms of spending leisure time with their children on holidays. However, the interviews were sometimes difficult to conduct as they contained highly emotional accounts ranging from expressions of great sadness and helplessness about broken relationships with their family, including adult children, to experiences of great joy of being an involved father and strengthening relationships with their children (e.g., Jenkins, 2009).

\section{Analysis and thematic framework}

A grounded theory approach drawing upon Hallman et al.'s (2007) research was used to discover fathers' perspectives regarding their holidays and involvement with their children following separation or divorce. Grounded theory specifically lends itself to the discovery of relatively unknown social phenomena (Glaser \& Strauss, 1967). A grounded theory process can be a means to allow both new perspectives regarding fathers' leisure, travel and involvement with their children following separation or divorce to emerge (Hallman et al., 2007; Jenkins, 2009), and fathers' own words to be used to inform theory and social processes under investigation (Glaser, 2001).

A constructivist approach to grounded theory was used for the analysis (Charmaz, 2000). This was carried out through manual coding in that data were initially coded by reading through the transcripts several times, while making notes that were then sorted into themes arising within and across non-resident fathers' responses. Categories and themes developed were thus grounded in the interview data but were also compared back to the existing literature. Theoretical saturation was deemed achieved when all emerging data fitted into the key themes (Morse, 1995) which in no priority order were: family bonding; facilitating family reconnection; repairing/mending of relationships; physical activities; father as entertainer; outdoor learning/generativity; broadening of horizons; facilitating family 
reconnection; and the intersects of work, parental responsibility and safety. The second author was not involved in the original coding of the transcripts, but did examine the final codes and ensure they appropriately reflected non-resident fathers' voices (e.g., Warner, Doble, \& Hutchinson, 2012).

Themes common to fathers and family holidays arising in previous research regarding fathers and their travel experiences (Costa, 2014b; Schänzel \& Smith, 2011) and in this study were: bonding/togetherness; physical activities; and father as entertainer. Given constraints of space, the themes more specific to leisure during non-resident father/parent holidays upon which we focus in this paper are: outdoor learning/generativity; broadening of horizons; facilitating family reconnection; repairing/mending of relationships; and responsibility/work/safety. It is these latter themes which are new to the family tourism literature and this is why they are the focus of the results and discussion section of this paper.

\section{Results and discussion}

All the non-resident fathers interviewed were 45-54 years of age and tertiary educated. All were heterosexual, except for one father who was gay. The children were all biological children of the fathers interviewed, and they ranged in age from 6-22 years old. One of the fathers involved (Gavin) had children who were adults, which represents a departure from many previous leisure studies which have tended to focus on fathers and families with children under 18 years of age. All the fathers had one to three children; three fathers had one child, three fathers had two children, and two fathers had three children (Table 1).

\section{INSERT TABLE 1 ABOUT HERE}

There were different non-resident father-child contact arrangements reflecting some diversity in parenting in separated families. Four of the participating fathers had fifty-fifty contact where care is equally shared among parents. Two fathers had standard contact whereby the fathers saw their children every alternate weekend and half of the school holidays. Two fathers had predominantly holiday-only contact because one father lived a long distance away from his children and the other father had a difficult relationship with his teenager. Five of the fathers grew up only in New Zealand and three of them were foreign born (English, American and Malaysian). This may have had an influence on the holiday destinations they each visited with their children as at the time of their interviews the latter 
three fathers had no family of their own in New Zealand. The incomes of the participating fathers ranged from below national average income (about NZ\$57,000) to high income (NZ\$200,000 and above), and this may also reflect the different holiday experiences discussed in the findings. Seven participants were previously married to the mother of their children (between 2-7 years' post-separation) except the gay father who still lives in close proximity to the mother (same apartment building). The fact that the non-resident straight fathers were previously married and the gay father maintained close contact to the mother may highlight committed family relationships in the past. All participants in the study valued their time with their children, and not only when they were at leisure or on holidays, trying to achieve emotional closeness and fulfil their own expectations of what it means to be a 'good father' (Kay, 2009). As Jerry explained:

I get really upset if I think I haven't spent enough time with my daughter and I get upset other people's kids ... don't get the opportunity to do things. So yeah it means a lot to me, it's the most important thing for me and it's the reason why I've stopped being a civil engineer so that I could spend more time with my family.

Matthew and Nicholas also both described the importance of their experiences on holidays in detail:

You know these children are growing mentally, physically and spiritually ... So I think all of those things need to be taught or experienced to be considered healthy and I try to encompass as much of that as possible with these holidays. The social aspect is to be in a place with new people, the learning aspect is the new activities and the placelenvironment. Physical is getting out there and doing some exercise and something healthy like running around and spiritual is just the whole feel good factor about family and being together and appreciating that not everyone is lucky enough to have it. (Matthew)

I know that a holiday with my children will provide me with unique experiences. I will be buried in the sand by my girls on Noosa beach or whatever and thrown in the water and walk around a rain forest, around Cairns, with the girls ... it's about the experience and the funny moments we have ... when you go on holiday you are going to have laughter, fun times and you are going to build good 
memories and there are going to be experiences that you will never have when you live in the everyday life. (Nicholas)

\section{Outdoor learning/generativity}

The extended time on holidays provided conscious opportunities for guiding their children (i.e., generativity; Shaw et al., 2008) by instilling values, traditions, and skills related to the outdoors. In a study focusing mainly on generative fathering and the connection between fathers and young children, Brotherson et al's (2005) review of the literature and research findings revealed several important patterns in fathers' involvement with their children. One pattern was that fathers described their sharing in activities with their children as an opportunity to teach or pass on skills through play or learning. Another pattern was that personal involvement in recreational activities in the outdoors, including camping, fishing, hunting, and picknicking) provided time for fathers to connect meaningfully with their children and to experience companionship and enjoyment and to bring fathers and their children closer together. Jerry, Mathew, Adam and Lloyd felt it was their responsibility to pass on skills that were often handed down to them from their fathers. This is about maintaining more masculinised holiday traditions of the great outdoors passed down by their fathers as documented by Turner (2015). An important aspect in New Zealand life is access to the rugged outdoors which is considered more of a masculine domain (Espiner, Gidlow, \& Cushman, 2011). According to the fathers interviewed, the mothers of the children tended not to expose the children to these outdoor experiences.

For Jerry, the opportunity for holidaying and experiencing the outdoors was particularly important because he is a trained outdoor recreation instructor who loves the outdoors and is concerned about his 11-year-old daughter spending too much time with electronic media inside the house. According to Jerry, the mother rarely plays with the daughter outside and Jerry feels it is his responsibility to provide these outdoor experiences:

... go caving, just exploring caves ... scramble up waterfalls, like if we're in the bush, adventures off track ... build bivouacs, just teach them about the bush a little bit, how to navigate ... camping responsibly like not going to the toilet next to the stream ...

Matthew has been taking his two children (boy and girl) to a remote bush and beach area in New Zealand for several years where there is no power but for a wood stove, and a spring is 
used to access fresh water. He uses this time with his children to teach them about wildlife, sea life, dam building, catching and cooking their own food, and he gets them to write journals to share in class:

We can spend quite a lot of time there just swimming and fishing and exploring. A couple of little streams we can go and dig; make little dams. So to teach the kids a little bit about how we can change the course of things ... that's been a very good education. We've taken a lot of photographs, made up little books so that they can take them back to their classes and read them to the class. We've combined the photographs with a little bit of text so they've helped to design the book and then read it to the class ... We were able to catch the food that we were eating most days. We were able to go out and collect paua and rock oysters and catch snapper, and we took up the basics like bread, flour and butter and things like that ...

\section{Broadening children's horizons and cultural perspectives}

An important aspect, especially evident in fathers' recounting of overseas holidays, was for the fathers to expose their children to different perspectives in life. The fathers felt it was their responsibility to broaden the cultural 'horizons' (Joel) or perspectives of their children by taking them outside of their known and comfortable world, to open their children's minds, and to learn about cultural respect and tolerance. Joel has travelled extensively with his teenage daughter in Asia and Europe:

If you ask me for one single reason why it's important [to have a holiday with my child], it's to widen the perspective of my daughter's life, to become more tolerant to the differences in culture and to start thinking that she and her family are not the only ones that exist in this world ... She needs to go around and look at these places, experience their cultural events, their religions, the different landscapes, mountains for example, different climates, different architecture, different colours ...

Joel also mentioned that: 
Every time I travel I also include staying in not so comfortable accommodations just to give them a little bit of a challenging environment ...

For Nicholas, his most recent holiday involved taking his two daughters (aged 12 and 16) back to where he was born and lived for his first five years in Fiji, exposing them to the culture and life there, and giving them a sense of 'here is my home':

They [my daughters] could meet people overseas that I grew up with. In Fiji, for instance, they met a Ratu chief who is building a dive resort in Fiji who is very charismatic and the kids absolutely loved him because he was a down-to-earth Fijian and he was showing what the Fijians are doing to help themselves. So they are seeing another culture, experiencing a Duvali festival in Fiji while we were there, seeing Indian people going to Hindu temples, hearing the singing from a Fijian church on a Sunday, a Methodist church, things that they would otherwise not hear or see ... were invaluable experiences for the girls.

Extended holidays overseas allowed fathers such as Joel and Nicholas to take their children out of their familiar environment, expose them to different cultures, ways of living and doing things.

\section{Family (re)connection}

An important aspect for the separated fathers born overseas and with no family of their own in New Zealand, was taking their children overseas to meet their relatives. In some instances, holidays overseas were the only opportunity to truly (re)connect the children face to face with their extended family. This is part of the VFR (visiting friends and relatives) phenomenon which is growing with increasing mobility (Backer, 2012), but which poses a particular problem for non-resident fathers. Fathers described these holiday and family reacquainting opportunities as expensive, but as particularly important in that their children are connected to their paternal family, particularly when there are long distances involved and when extended family lived overseas.

Lloyd, an American, described taking his two sons back to the United States every year during the northern hemisphere summer (New Zealand winter), a financially difficult but necessary commitment to ensure that family relationships are established: 
So while we were in the States with the cousins they're like playing baseball in the back yard and my brother is pretty good at teaching them how to play sports .... We took all the cousins to the movies but it's having these shared experiences that you can sort of draw on in 20,30, 40 years from now; 'remember when we did bla bla bla' ... It's all about the experiences ...

For another father (Jerry), the holidays allow him to take his daughter to Korea where his brother and family live. It is important for Jerry (who was born in England but grew up in New Zealand) to establish and maintain these relationships to his side of the family:

Just to give her access to family. Like my brother [living in Korea] came over here last week ... So it's important for her to have family because her mother's family ... they are not child liking people .... I don't necessarily get on too well with my brother but it's very good for her to have an uncle around. I grew up without family. I mean I had a brother but that was it, brother, mother, father, everyone else lived in England and that had a big impact on me ... so I think it's important for her to meet them and know them.

Holidays, then, for these overseas-born fathers, allow them to (re)connect with their side of the family and ensure that their children get to know and have links to their paternal and broader families.

\section{Repairing/mending of relationships}

Living apart from their children who are under the more regular influence and guidance of their mother can bring out feelings of inadequacy as a parent and deep emotional turmoil in some men (Smyth, 2005a; Stewart, 1999). There is also the emotional pain experienced by some fathers who feel rejected or criticised by especially their older children and seek holidays as an opportunity to mend these relationships. Gavin experiences these feelings and emotions, and they vary with each child and over time. Gavin went on a skiing holiday to Japan with his teenage son and experienced a great improvement in their relationship. However, his relationship with his two adult daughters has broken down and they refused to go along on that holiday. He initially described how his relationship with his son had changed: 
Males in general, they don't tend to talk deeply to each other about their feelings and stuff. We were able to talk and you know have fun together and that's worth a million dollars really and being able to do something that we both love doing together as well and now it's actually really solidified the relationship we have ... I have just moved house and he was saying 'there is a spare bedroom'. He was looking at that room thinking, 'I can stay here'.

Gavin then added that spending an extended period of time together doing activities that they both enjoyed considerably improved their relationship and allowed Gavin to feel much closer to his son:

We did things together, we re-established that connection between us ... Since the holiday he has been a lot more proactive in getting me involved in his life ... so you know he is sending me texts all the time where he is playing cricket or where he is playing rugby ... we are meeting up regularly and he is helping me now, where, you know, perhaps last year it was like pulling teeth ... he wants to be involved and be part of being with me so ... I think that holiday had a lot to do with it and I imagine if I was able to take the girls on holiday that would improve things with them as well.

Holidays, thus, can become a time and space to repair father-child relationships. Holidays can also be opportunities to work on personal relationships because of that one-on-one contact and opportunity for closeness in a leisure oriented setting. Nicholas, for example, stated: 'The holidays are an opportunity to find where they are weak and where their lives need propping up. That's why I think the holidays are critical; time for one-on-one.' It seems that holidays as opposed to shorter weekends together (Costa, 2014a) may allow for the extended personal time together that is needed for fathers to help mend and repair fissures in relationships or personal issues with children, and to experience a wider range of activities and share and indulge in a wider array of aspects of each family member's life (Jenkins, 2009; Swinton, et al., 2008, 2009).

\section{Responsibility of non-resident fatherhood}

There were also comments about the work and responsibility experienced by some fathers in ensuring the children are safe, fed and looked after while on holiday which are usually only 
associated with motherhood (e.g. Mottiar \& Quinn, 2012; Small, 2005). For example, Josh prefers to holiday with his two daughters (aged 9 and 11) by doing day trips from home as they are within walking distance of a beautiful beach and the mother regularly takes the children on trips around the country and to Australia. An added constraint is that one of his daughters has a food allergy and it is easier to cater for her at home:

To be honest taking them away somewhere isn't a holiday for me. It's just an extension of what we do and so the parenting doesn't go away. So the holiday is just an extension of work ... I guess that's the thing about leisure and work and parenting is that it's just a continuum. You don't stop until they are sound asleep at night.

Lloyd also commented on the constant responsibility of looking after the children. Both Josh and Lloyd have fifty-fifty contact with their children and therefore spend a significant amount of their time with their children. Holidays then become much more of an extension to daily life and parenting commitments, as expressed by Lloyd who has two sons (aged 7 and 9): ' $I$ love my kids but I am not like "this is the most awesome thing ever to build a sand castle". So ... there is an aspect of it where I think of it as a responsibility'.

In the absence of mothers, non-resident fatherhood is also associated with the neverending physical and emotional work both at home and when travelling of being a responsible parent. Jerry, who has fifty-fifty care of his 11-year-old daughter, described the situation this way:

Just the opportunity to do things because the opportunity is there, but we make up excuses that we don't have time to do these things and really it is all made up. It is the most important thing and we can fill up our time with other things later. I mean I only have one daughter, probably will not have another one.

Although holidays can also mean an extension of work and responsibilities, all fathers embraced the opportunity to spend extended time with their children but in different ways. Josh, for example, reflected on the differences between a father who sees his children regularly and a father who only has intermittent contact: 
I mean it might be different if I was the Sunday dad or something like that and I think that might be a big difference. And what you might find if I had them for a weekend every two weeks or something or I hadn't seen them for three months then I would want to go do something special, but I don't feel the need to go do something special because I have a lot of time with them.

This alludes to differences in how father-child contact arrangements can affect non-resident fathers' holiday behaviours in that with holiday-only contact there will be more emphasis on making the most of the extended time period. The other factor is the holiday experiences of the children when with their mother and not their father. Fathers felt less of a responsibility to provide certain holiday experiences when the mothers provided them; for example, taking the children to a theme park in Australia (Josh). However, fathers felt a responsibility to provide outdoor or overseas holiday experiences for their children when the mothers were unable or unwilling to do that. The level of responsibility felt by the fathers in providing certain holiday experiences was influenced by various factors, but all fathers in our study were willing to step in when they felt a need to take on responsibility to widen children's leisure and holiday experiences and their learning environments.

\section{Conclusions: Leisure holidays and fatherhood}

Non-resident fathers' stories are central to understanding their holidays with their children as a social context and setting for non-resident fatherhood. They provided insights into the extent and nature of fathers' contact with their children, and fathers' holiday experiences and the meanings of those experiences. Although our findings have provided new and nuanced insights into non-resident fathers' engagement and contact with their children, the research findings have some important limitations, which mean we cannot generalise the findings. Nonetheless, we can indicate some areas for further research and draw comparisons with previous research in other leisure and holidays contexts, and reveal valuable research opportunities.

The fathers interviewed were not a random or representative sample. The fathers were all aged 45-54 years and tertiary educated, and their children varied in age. The diverse family forms that are evident in families where there is a non-resident father were not evident in this study, and the holiday experiences of the children and fathers in this study were greatly 
influenced by the fathers' incomes and contact arrangements. Despite these limitations, it is very evident that much work on the fascinating and important social relationships arising in diverse families and their family holidays remains to be done.

Our explorative research indicates leisure holidays may be an important part of nonresident fathers' ways to maintain involvement with their children after separation and divorce (Hallman et al., 2007), particularly in the absence of important daily family leisure activities (Buswell et al., 2012). Those holidays can help restore a balance within family functioning and achieve greater family cohesion which is usually provided by core or everyday leisure in a family systems framework (Zabriskie \& McCormick, 2001). There is an underexplored aspect of fatherhood that is perhaps more specific to holidays because it allows fathers to experience extended periods of time in leisure contexts and holiday settings with their children, to negotiate values and develop skills, to build lasting relationships (also with overseas family)and share memories, and to be a good father.

There were emerging themes of fatherhood that are common within the family tourism literature, such as the ubiquitous notion of bonding and spending time together (Schänzel, Yeoman, \& Backer, 2012), the importance of memory formation (Shaw et al., 2008), engaging in activities that are more active and physical, or leisure-based fathering (Kay, 2006, 2009), and providing fun experiences where the father is considered more as the entertainer (Schänzel \& Smith, 2011), often in the outdoors. In our research these themes were confirmed and extended. However, a greater understanding and comparison can only be made through more detailed studies of a larger and more representative sample, or, for example, through studies of specific cohorts of non-resident fathers (e,g, fathers with children of specific gender or ages; fathers who have re-partnered) or fathers with particular contact arrangements (e.g. contact every second weekend; 50-50 care). Holidays for the fathers, just as family tourism in general, are also about family practices (Hall \& Holdsworth, 2014) that are publically displayed when on holiday. Display is an important part of relationships so that the familylike qualities are positively established (Finch, 2007). The social practice of 'doing family things' such as skiing and fishing together (rather than 'being' a family) does then get constituted as a family practice tied to fatherhood and being a good father which differs from the routines of daily life.

Some challenging themes also emerged, including the overall sense of responsibility or work in ensuring that children are safe and cared for on holiday. It means there are amongst our sample of non-resident fathers benefits (building relationships with their children) and 
constraints (work, safety and privacy) to their holiday experiences that require more detailed attention. Research could be undertaken across a larger sample incorporating more diverse family contexts and fathering arrangements, or could focus on very specific cohorts of nonresident fathers (e.g. low income; rural; professional; unemployed). It is, then, not just the 'never-ending domestic and emotional work of motherhood both at home and when travelling' (Small, 2005), but in the absence of mothers it also applies to non-resident fatherhood. There were also voicings of the financial costs of holidays, the work and responsibility involved in facilitating holidays and fulfilling children's expectations when spending time away from home together, and the need for fathers to find opportunities to have time alone just as mothers do (Fountain et al., 2015).

The fathers involved in this research, and the extent and nature of their contact with their children, display typically gendered parenting arrangements, which often promote the prevalence and importance of leisure and holidays. Our research points to three valuable and broad lines of inquiry. Firstly, better recognise and understand the significant differences among families who travel. Secondly, examine leisure holidays with regards to single and non-resident parents and their families, and assess the significance that extended time on holidays might have for family leisure and family relationships. This also has important implications for the hospitality and tourism industry which still largely addresses the nuclear family even though family structures and parenting arrangements have changed dramatically over the past few decades, are now very diverse and, and as OECD (2011) and other evidence indicates, are continuing to change. Thirdly, include children's/young people's perspectives on their father/son-daughter relationship experiences when on holiday.

In our study, the positive experiences arising from holiday-based interactions increased many non-resident fathers' happiness and sense of contribution as a parent, and indeed as a father. Our findings support existing research that most non-resident fathers want to be good fathers regardless both of the they type and nature of contact fathers have with their children and of other life circumstances, and that family leisure is an important means of helping fathers be good dads (Jenkins, 2009). Our exploratory study demonstrates the potential wider contribution that leisure holidays can make as a social force within single fatherhood/parenthood, childhood and contemporary family life, and we argue it is a phenomenon worthy of more detailed investigation and more attention in the leisure and tourism literature. Like Mitchell and Lashcewicz (2015, p. 142), but in a broader context than their research described earlier, we find the leisure, recreational and travel dimensions of fathers' engagement with their children to be a rich and rewarding focus for research on what 
dads do with their children, and in better understanding fathering in diverse contexts and settings.

\section{References}

Allen, S., \& Daly, K. (2007). The effects of father involvement: An updated research summary of the evidence. Guelph, Canada: University of Guelph.

Amato, P.R. (2001). Children of divorce in the 1990s: An update of the Amato and Keith (1991) meta-analysis. Journal of Family Psychology, 15, 350-370.

Amato, P.R., \& Gilbreth, J.G. (1999). Nonresident fathers and children's well-being: A metaanalysis. Journal of Marriage and Family, 61, 557-573.

Anderson, J. (2001). Mothers on family activity holidays overseas. In S. Clough \& J. White (Eds.), Women's leisure experiences: Ages, stages and roles (pp. 99-112). Eastbourne, England: Leisure Studies Association.

Australian Institute of Family Studies (AIFS) (2003). Family structure, child outcomes and environmental mediators: An overview of the development in diverse families study. Research Paper No. 30 - February, Canberra: AIFS.

Backer, E. (2012). VFR travel: It is underestimated. Tourism Management, 33, 74-79.

Blankenhorn, D. (1995). Fatherless America: Confronting our most urgent social problem. Scranton, PA: Harper Collins.

Brotherson, S.E., Dollahite, D.C. \& Hawkins, A.J. (2005). Generative fathering and the dynamics of connection between fathers and their children, Fathering 3(1) pp.1-28.

Buswell, L., Zabriskie, R. B., Lundberg, N., \& Hawkins, A. J. (2012). The Relationship Between Father Involvement in Family Leisure and Family Functioning: The Importance of Daily Family Leisure. Leisure Sciences, 34(2), 172-190.

Cabrera, N.J., Tamis-LeMonda, C.S., Bradley, R.H., Hofferth, S., \& Lamb, M.E. (2000). Fatherhood in the twenty-first century. Child Development, 71, 127-136.

Carr, N. (2006). A comparison of adolescents' and parents' holiday motivations and desires. Tourism and Hospitality Research, 6, 129-142.

Carr, N. (2011). Children's and families' holiday experiences. London, England: Routledge.

Caruana, C., \& Ferro, A. (2004). Points of convergence. In B. Smyth (Ed.), Parent-child contact and post-separation parenting arrangements (Research Report No. 9). Melbourne, Australia: Australian Institute of Family Studies (AIFS). 
Charmaz, K. (2000). Grounded theory: Objectivist and constructivist methods. In N.K.

Denzin \& Y.S. Lincoln (Eds.), Handbook of qualitative research (pp. 509-535, 2nd ed.). Thousand Oaks, CA: Sage.

Costa, R.P. (2014a). Backpacks, driving, fun and farewell: Examining the ritual experience of the weekend amongst non-resident parents and their children. Leisure Studies, 33, $164-184$.

Costa, R. (2014b). Ephemeral masculinities? Tracking men, partners and fathers in the geography of family holidays. In T. Thurnell-Read \& M. Casey (Eds.), Men, masculinities, travel and tourism (pp. 120-138). Basingstoke, England: Palgrave Macmillian.

Denzin, N.K. \& Lincoln, Y.S. (Eds.). (2000). Handbook of qualitative research. Thousand Oaks, CA: Sage.

deVaus, D. (2004). Diversity and change in Australian families: Statistical profiles. Melbourne, Australia: Australian Institute of Family Studies.

Espiner, S., Gidlow, B., \& Cushman, G. (2011). Outdoor recreation and gendered space: The case of men's enthusiasms for hunting, fly-fishing and scuba diving. Annals of Leisure Research, 14, 176-193.

Families Commission. (2008). The Kiwi nest: 60 years of change in New Zealand families. Wellington, New Zealand: Families Commission.

Finch, J. (2007). Displaying Families. Sociology, 41, 65-81.

Fountain, J., Schänzel, H., Stewart, E., \& Körner, N. (2015). Family experiences of visitor attractions in New Zealand: Differing opportunities for 'family time' and 'own time'. Annals of Leisure Research, 18, 342-358.

Fu, X., Lehto, X., \& Park, O. (2014). What does vacation do to our family? Contrasting the perspectives of parents and children. Journal of Travel \& Tourism Marketing, 31, 461-475.

Glaser, B.G. (2001). The grounded theory perspective: Conceptualization contrasted with description. Mill Valley, CA: Sociology Press.

Glaser, B.G., \& Strauss, A.L. (1967). The discovery of grounded theory: Strategies for qualitative research. New York, NY: Aldine.

Gram, M. (2005). Family holidays: A qualitative analysis of family holiday experiences. Scandinavian Journal of Hospitality \& Tourism, 5, 2-22.

Hall, S. M., \& Holdsworth, C. (2014). Family Practices, Holiday and the Everyday. Mobilities, 1-19. 
Halle, T., Moore, K., Greene, A., \& LeMenestrel, S.M. (1998). What policymakers need to know about fathers. Policy \& Practice of Public Human Services, 56(3), 21-35.

Hallman, M., Dienhart, A., \& Beaton, J. (2007). A qualitative analysis of fathers' experiences of parental time after separation and divorce. Fathering, 5, 4-25.

Harrington, M. (2009). Sport mad, good dads: Australian fathering through leisure and sport practices. In T. Kay (Ed.), Fathering through sport and leisure (pp. 51-72). London, England: Routledge.

Jenkins, J.M. (2009). Nonresident fathers' leisure with their children. Leisure Sciences, 31, $255-271$.

Jenkins, J. (2013). Bringing leisure in: The benefits and importance of leisure to non-resident fatherhood and parent-child contact. In T. Freire (Ed.), Positive leisure science (pp. 175-191). Dordrecht, the Netherlands: Springer Netherlands.

Jenkins, J., \& Lyons, K. (2006). Nonresident fathers' leisure with their children. Leisure Studies, 25, 219-232.

Kay, T. (2006). Where's dad? Fatherhood in leisure studies. Leisure Studies, 25, 133-152.

Kay, T. (Ed.). (2009). Fathering through sport and leisure. London, England: Routledge.

Lyons, K. (2006). Wolves among sheep? The role of men in a feminist leisure studies. Leisure Sciences, 28, 305-309.

McCarville, R. E., Shaw, S. M., \& Ritchie, M. (2013). Shopping as leisure: a study of avid shoppers. World Leisure Journal, 55(2), 167-178.

Mitchell, J., \& Lasewicz, B. (2015). More than a pal: The generative leisure work of fathers raising children with autism spectrum disorder. Fathering, 13.

Morse, J.M. (1995). The significance of saturation. Qualitative Health Research, 5, 147-149.

Mottiar, Z., \& Quinn, D. (2012). Is a self-catering holiday with the family really a holiday for mothers? Examining the balance of household responsibilities while on holiday from a female perspective. Hospitality and Society, 2, 197-214.

Obrador, P. (2012). The place of the family in tourism research: Domesticity and thick sociality by the pool. Annals of Tourism Research, 39, 401-420.

Organisation for Economic Co-operation and Development [OECD]. (2011). Doing better for families. Retrieved from http://www.oecd.org/els/soc/doingbetterforfamilies.htm

Phillimore, J., \& Goodson, L. (Eds.). (2004). Qualitative research in tourism: Ontologies, epistemologies and methodologies. London, England: Routledge.

Pringle, R., Kay, T., \& Jenkins, J.M. (2011). Masculinities, gender relations and leisure studies: Are we there yet? Annals of Leisure Research, 14, 107-119. 
Rojek, C. (2005). Leisure theory: Principles and practice. Basingstoke, England: Palgrave.

Schänzel, H.A., \& Smith, K.A. (2011). The absence of fatherhood: Achieving true gender scholarship in family tourism research. Annals of Leisure Research, 14, 129-140.

Schänzel, H.A., \& Yeoman, I. (2015). Trends in family tourism. Journal of Tourism Futures, $1(2), 1-6$.

Schänzel, H., Yeoman, I., \& Backer, E. (Eds.). (2012). Family tourism: Multidisciplinary perspectives. Bristol, England: Channel View.

Shaw, S.M. (1997). Controversies and contradictions in family leisure: An analysis of conflicting paradigms. Journal of Leisure Research, 29, 98-112.

Shaw, S.M., Havitz, M.E., \& Delemere, F.M. (2008). I decided to invest in my kids' memories: Family vacations, memories, and the social construction of the family. Tourism Culture \& Communication, 8, 13-26.

Small, J. (2005). Women's holidays: Disruption of the motherhood myth. Tourism Review International, 9, 139-154.

Smyth, B. (2004a). Postseparation fathering: What does Australian research tell us? Journal of Family Studies, 10, 20-49.

Smyth, B. (Ed.). (2004b). Parent-child contact and post-separation parenting arrangements (Research Report No. 9). Melbourne, Australia: Australian Institute of Family Studies.

Smyth, B. (2005a). Post-separation patterns of parenting in Australia: Who opts for what and why? (Doctoral dissertation, Swinburne University of Technology, Australia).

Smyth, B. (2005b). Parent-child contact in Australia: Exploring five different post-separation patterns of parenting. International Journal of Family Law, Policy and the Family, 19, $1-22$.

Stewart, S.D. (1999). Disneyland dads, Disneyland moms? How nonresident parents spend time with absent children. Journal of Family Issues, 20, 539-556.

Such, E. (2006). Leisure and fatherhood in dual-earner families. Leisure Studies, 25, 185-199.

Such, L. (2009). Fatherhood, the morality of personal time and leisure-based parenting. In T.

Kay (Ed.), Fathering through sport and leisure (pp. 73-77). London, England:

Routledge.

Swinton, A., Freeman, P., Zabriskie, R., \& Fields, P. (2008). Nonresident fathers' leisure patterns during parenting time with their children. Fathering, 6, 205-225.

Swinton, A., Freeman, P., Zabriskie, R., \& Fields, P. (2009). Divorce and recreation: Nonresident fathers' leisure during parenting time with their children. In T. Kay (Ed), Fathering through sport and leisure (pp. 145-163). London, England: Routledge. 
Thurnell-Read, T., \& Casey, M. (Eds.). (2014). Men, masculinities, travel and tourism. Basingstoke, England: Palgrave Macmillian.

Turner, W.C. (2015). Family and the great outdoors. Lilburn, US: Fairmont Press.

Warner, G., Doble, S.E., \& Hutchinson, S.L., (2012). Successful aging in transition: Contemplating new realities. World Leisure Journal, 54, 255-268.

Wearing, S.L., Wearing, J., McDonald, M., \& Wearing, M. (2015). Leisure in a world of 'com-pu-pu-pu-pu-pu-pu-pu-pu-pu-pu-puter, puter games': A father and son conversation. Annals of Leisure Research, 18, 219-234.

Zabriskie, R. B., \& McCormick, B. P. (2001). The influences of family leisure patterns on perceptions of family functioning. Family Relations, 50(3), 281-289. 